\title{
LA LLAMADA A LA VIDA CRISTIANA EN LOS DOCUMENTOS DE LA JMJ MADRID 2011
}

DOI: https://doi.org/10.52039/seminarios.v58i203.321

\author{
Ángel Matesanz Rodrigo*
}

La Jornada Mundial de la Juventud como tal, en toda su preparación y desarrollo -iy en sus consecuencias!-, se concibe como una gran llamada dirigida a los jóvenes a vivir la vida en comunión con Jesucristo, con su persona y su misión; eso está desde luego en la intención del Papa, que es quien la convoca. En las recomendaciones que reciben los organizadores figuran los objetivos pastorales de la JMJ; entre ellos, el redescubrimiento de la vocación bautismal por parte de los jóvenes, llamados a ser miembros activos de la Iglesia, convirtiéndose ellos mismos en evangelizadores y misioneros del mundo contemporáneo; y también la atención a la dimensión vocacional para impulsar la pastoral juvenil.

En el caso de Madrid 2011, el Papa declaraba el propósito de su viaje nada más llegar al aeropuerto de Barajas, en su saludo a las autoridades: «Vengo a encontrarme con millares de jóvenes de todo el mundo, católicos, interesados por Cristo o en busca de la verdad que dé sentido genuino a su existencia... Para exhortar a los jóvenes a encontrarse personalmente con Cristo Amigo y así, radicados en su Persona, convertirse en sus fieles seguidores y valerosos testigos».

Ciertamente, la llamada de Dios a los jóvenes ha resonado nítida y vigorosa en las palabras del anciano Benedicto XVI, y ha sido tema siempre presente en el argumento de sus mensajes.

\section{LA LLAMADA DE DIOS ESTÁ INSCRITA EN LO HONDO DE NUESTRO SER}

La llamada de Dios, que tan insistentemente recuerdan las palabras del Papa, no se refiere en primer lugar a una tarea concreta, aunque termine por incluirla. Se refiere a toda la persona, lo que se es y lo que se tiene, y a toda la vida: pensamientos, sentimientos, decisiones y operaciones; al yo más íntimo, que se sabe concernido por el Tú divino.

Está inscrita en nuestro propio ser: llamada a buscar la verdad y el bien, a colaborar en el cultivo y embellecimiento de la creación, a ser interlocutores de Dios, dialogar con él y amarle. Inscrita en nuestro propio ser está también la ca-

* Vicario para la aplicación del Sínodo de la archidiócesis de Madrid. 
pacidad para responder. Podemos responder a esta llamada porque Dios nos ha creado así: libres, a imagen suya, protagonistas, responsables y no meros ejecutores ciegos, capaces de escuchar y de responder.

La llamada a ser personas es la más radical y más fundamental que se dirige al ser humano. Si no la hubiéramos recibido no seríamos nada, ni existiríamos. Puede considerarse como la más fundamental; otras llamadas son posteriores y son como modulaciones en las que ésta se desarrolla y se concreta.

La llamada de Dios está en nuestro ser. Sólo hay que saber discernirla e identificarla. La presión ambiental no lo hace fácil, porque se han erigido como máximos valores la posesión de bienes materiales y el confort y el placer que pueden proporcionar, y parece que sólo quedaran energías para buscar lo que conduce a ello. Se desprecia como inútil -sean cosas, o instituciones, o personas- todo lo que no lo favorece.

\section{Buscar algo más}

Ya en el Mensaje para la JMJ 2011, de agosto del año anterior, quiere Benedicto XVI ayudar a los jóvenes a discernir la llamada de Dios: «Desear algo más que la cotidianidad de un empleo seguro y sentir el anhelo de lo que es realmente grande forma parte del ser joven. ¿Se trata sólo de un sueño vacío, que se desvanece cuando uno se hace adulto? No, el hombre en verdad está creado para lo que es grande, para el infinito. Cualquier otra cosa es insuficiente. San Agustín tenía razón: Nuestro corazón está inquieto, hasta que no descansa en ti. El deseo de la vida más grande es un signo de que él nos ha creado, de que llevamos su huella» (n. 1). Inmediatamente fue criticado por atreverse a mostrar a los jóvenes otras realidades humanas, otros bienes distintos de los materiales.

El Papa no da por buena la opinión, tan extendida, de que los jóvenes sean sólo alocados y superficiales. Al contrario, reconoce su búsqueda -impulsada quizá más por la pasión que por la razón-, los toma en serio y los valora. Y al decírselo a los jóvenes en el saludo de bienvenida en Cibeles, les invita a pensar y perseverar en la búsqueda, y con toda sinceridad les ofrece la orientación que le guía a él en su vida: «Tenéis interrogantes y buscáis respuestas. Es bueno buscar siempre. Buscar sobre todo la Verdad que no es una idea, una ideología o un eslogan, sino una Persona, Cristo, Dios mismo que ha venido entre los hombres». Y saludando en alemán, les promete: «En estos días tendremos nuevamente esta experiencia: es Cristo quien da verdaderamente sentido a nuestra vida».

\section{¿Buscar siempre?}

No siempre la llamada de Dios resuena con claridad en nuestra conciencia. A veces puede resultar desconcertante e incluso escandalosa, porque parece que la dignidad humana, la imagen de Dios, la libertad están oscurecidas y des- 
dibujadas. También esta dificultad la ha tenido en cuenta el Papa. En la Fundación Instituto San José decía: «La juventud, lo hemos recordado otras veces, es la edad en la que la vida se desvela a la persona con toda la riqueza y plenitud de sus potencialidades, impulsando la búsqueda de metas más altas que den sentido a la misma. Por eso, cuando el dolor aparece en el horizonte de una vida joven, quedamos desconcertados y quizá nos preguntemos: ¿Puede seguir siendo grande la vida cuando irrumpe ella el sufrimiento?».

La respuesta es: Sí, sin duda. Jesucristo nos persuade. Él es el Camino incontestable para reconocer y vivir incondicionalmente en todo caso la dignidad de la persona. «Jesús y, siguiendo sus huellas, su Madre Dolorosa y los santos son los testigos que nos enseñan a vivir el drama del sufrimiento para nuestro bien y la salvación del mundo. Estos testigos nos hablan, ante todo, de la dignidad de cada vida humana, creada a imagen de Dios. Ninguna aflicción es capaz de borrar esta impronta divina grabada en lo más profundo del hombre. Y no solo: desde que el Hijo de Dios quiso abrazar libremente el dolor y la muerte, la imagen de Dios se nos ofrece también en el rostro de quien padece».

\section{Buscar, ¿por qué?}

En la homilía de la celebración de bienvenida en Cibeles, les daba la clave para interpretar esos sentimientos que anidan en su corazón y no se dejan acallar por nada: son semilla de plenitud que Dios ha sembrado en ellos. «Vuestro entusiasmo y alegría, vuestros deseos de ir a más, de llegar a lo más alto, hasta Dios, tienen siempre futuro cierto, porque la vida en plenitud ya se ha aposentado dentro de vuestro ser». No es una hipótesis ni una teoría. Es la afirmación rotunda de una certeza, que repetirá en la predicación de la Vigilia en Cuatro Vientos: «Sí, queridos amigos, Dios nos ama. Ésta es la gran verdad de nuestra vida y que da sentido a todo lo demás. No somos fruto de la casualidad o la irracionalidad, sino que en el origen de nuestra existencia hay un proyecto de amor de Dios».

El Papa habla a los jóvenes en serio. No trata de cautivarlos con halagos ni pretende ganarlos recurriendo simplemente a la retórica o a trucos que hagan aflorar la emoción. Les ofrece argumentos, les muestra la realidad completa y auténtica de la persona, visible únicamente, es verdad, a la luz de la fe. En la misma homilía de Cibeles les explica: «Nosotros sabemos bien que hemos sido creados libres, a imagen de Dios, precisamente para que seamos protagonistas de la búsqueda de la verdad y del bien, responsables de nuestras acciones, y no meros ejecutores ciegos, colaboradores creativos en la tarea de cultivar y embellecer la obra de la creación. Dios quiere un interlocutor responsable, alguien que pueda dialogar con él y amarle. Por Cristo lo podemos conseguir verdaderamente y, arraigados en Él, damos alas a nuestra libertad. ¿No es este el gran motivo de nuestra alegría? ¿No es este un suelo firme para edificar la civilización del amor y de la vida, capaz de humanizar a todo hombre?». 


\section{Caminamos en Cristo}

Ciertamente puede decirse que éste es uno de los elementos importantes del mensaje que el Papa ha querido transmitir a los jóvenes tanto en la JMJ 2011 como a lo largo de su pontificado. Los jóvenes tienen que saberlo: Jesucristo está a favor nuestro, creer en él humaniza, vivir unidos a él nos da plenitud. Si lo saben, lo buscan. Y el que busca, encuentra. Por eso, en la Vigilia en Cuatro Vientos, insiste dirigiéndose a los jóvenes de habla alemana: «En el fondo, lo que nuestro corazón desea es lo bueno y bello de la vida. No permitáis que vuestros deseos y anhelos caigan en el vacío, antes bien haced que cobren fuerza en Cristo».

Jesucristo nos revela todo: quiénes somos, qué esperanza se nos concede, a qué nos llama Dios. En él, Hijo de Dios hecho hombre, se nos aclara decisivamente cómo responder a la llamada que Dios nos dirige a ser y a vivir como personas. Lo había dicho el Papa en Cibeles: «Él es el único que conoce de verdad el camino del hombre hacia Dios, porque es él quien lo ha abierto para nosotros; hemos sido creados para que, por ese camino, podamos alcanzar la vida auténtica».

Al recordar -o enseñar- a los jóvenes estos elementos básicos de la experiencia de fe de la Iglesia, Benedicto XVI aviva la búsqueda de los jóvenes y la orienta. Dios no nos pide un poco de nuestro tiempo ni realizar algunas buenas acciones ni ejercitar unas virtudes. En realidad Dios no nos pide nada, pero lo espera todo de nosotros: que lo reconozcamos a él como Padre y que, unidos a Jesucristo, consintamos en vivir nuestra condición de hijos, confiados y fieles.

\section{LA LLAMADA DE DIOS SE CLARIFICA Y SE CONCRETA EN JESUCRISTO}

El anuncio de Jesucristo, la necesidad del encuentro personal con él, la transformación que se produce en la vida de quien cree en él, ése ha sido el núcleo de todas y cada una de las intervenciones del Papa, el nervio central de su mensaje a los jóvenes en la JMJ de Madrid. Como hemos recordado, lo declaró en el aeropuerto de Barajas, nada más bajar del avión: «Llego como Sucesor de Pedro... para anunciar que Jesucristo es el Camino, la Verdad y la Vida. Para impulsar el compromiso de construir el Reino de Dios en el mundo, entre nosotros. Para exhortar a los jóvenes a encontrarse personalmente con Cristo Amigo y así, radicados en su Persona, convertirse en sus fieles seguidores y valerosos testigos».

Desde el principio de su pontificado ha insistido Benedicto XVI en esta convicción. «No se comienza a ser cristiano por una decisión ética o una gran idea, sino por el encuentro con un acontecimiento, con una Persona, que da un nuevo horizonte a la vida y, con ello, una orientación decisiva», avisaba al comenzar su primera encíclica Deus caritas est. 
Un obstáculo que puede estorbar el encuentro con el Señor es el prejuicio de la «imposible contemporaneidad». El Papa afronta esta dificultad en la homilía de la Misa en Cuatro Vientos: «¿Cómo es posible que alguien que ha vivido sobre la tierra hace tantos años tenga algo que ver conmigo hoy?». No responde inmediata y directamente a la objeción, sino en el desarrollo de la homilía. "Ciertamente -dice- son muchos en la actualidad los que se sienten atraídos por la figura de Cristo y desean conocerlo mejor. Perciben que él es la respuesta a muchas de sus inquietudes personales. Pero ¿quién es él realmente?».

Son los primeros elementos de la respuesta: sentirse atraídos, desear conocerlo, percibir que acalla y desborda las propias inquietudes... Todo esto está señalando a Alguien. Una cosa es que resulte enigmático y otra que no exista para mí ni pueda existir. Más tarde se irá comprendiendo que esa Persona Misteriosa que tanto nos inquieta y atrae es el Viviente que, resucitado, empezó ya a ser contemporáneo, de una manera nueva, para sus propios discípulos que habían convivido con él en su vida terrena: Cefas, los Doce, más de quinientos hermanos, el mismo Pablo que transmite el testimonio... (cf. 1 Cor 15). En su Palabra, en los sacramentos, en el servicio a los pobres, en la comunidad de sus discípulos, percibimos su mensaje y su Presencia, nos sale al encuentro y nos llama.

\section{Jesucristo se acerca y se revela}

En los mensajes sobre Jesucristo de Benedicto XVI a los jóvenes la palabra clave es «encuentro personal». Se podría poseer toda la información sobre Jesús, su contexto histórico, su vida y su doctrina, y no tener fe. Incluso se podría observar una conducta de acuerdo con la moral cristiana y, sin embargo, no ser discípulo suyo. Una cosa es estudiar y controlar intelectualmente el fenómeno Jesús y su influencia a lo largo de la historia, y otra muy distinta dejarse «controlar» por él, sentirse atraído y seducido por él, confiarse a él y seguirlo.

A propósito del evangelio de aquel domingo, comenta el Papa dos modos distintos de conocer a Cristo. «El primero consistiría en un conocimiento externo, caracterizado por la opinión corriente... Es decir, se considera a Cristo como un personaje religioso más de los ya conocidos... La fe va más allá de los simples datos empíricos o históricos, y es capaz de captar el misterio de la persona de Cristo en su profundidad». "La fe no es fruto del esfuerzo humano, de su razón -les dice el Papa a los jóvenes en la homilía de la Misa de Cuatro Vientos-, sino que es un don de Dios... Tiene su origen en la iniciativa de Dios, que nos desvela su intimidad y nos invita a participar de su misma vida divina. La fe no proporciona solo alguna información sobre la identidad de Cristo, sino que supone una relación personal con él, la adhesión de toda la persona, con su inteligencia, voluntad y sentimientos, a la manifestación que Dios hace de sí mismo». 
Esta observación es particularmente oportuna para la mentalidad actual. Estamos acostumbrados a fiarnos únicamente de lo que podemos verificar, a controlar los efectos que nosotros mismos provocamos, a manipular las cosas e incluso a las personas para conseguir lo que pretendemos. Queremos ser los protagonistas absolutos de toda nuestra vida y llegamos a imaginar que también son así las cosas respecto de Jesucristo, como si fuéramos nosotros los que decidimos si él es el Señor o no, o cuándo lo es.

Jesucristo se nos acerca hasta hacerse uno de nosotros porque él quiere; no es un logro nuestro. El encuentro personal con Cristo no consiste en que se una a nosotros y secunde nuestros deseos; justo al contrario, se trata de escuchar su llamada, desear responderle, dejarnos atraer por él, adherirnos a él y seguirlo. El mismo Señor, poco antes de morir, se lo aclaró a sus discípulos: «No sois vosotros los que me habéis elegido, soy yo quien os he elegido» (Jn 15, 16).

\section{Perseverar en la escucha}

El encuentro personal con Jesucristo supone, en primer lugar, escucharle. "Hemos oído un pasaje del Evangelio -dice Benedicto XVI en su Homilía en Cibeles- en que se habla de acoger las palabras de Jesús y de ponerlas en práctica. Hay palabras que solamente sirven para entretener, y pasan como el viento; otras instruyen la mente en algunos aspectos; las de Jesús, en cambio, han de llegar al corazón, arraigar en él y fraguar toda la vida. Sin esto, se quedan vacías y se vuelven efímeras. No nos acercan a él. Y, de este modo, Cristo sigue siendo lejano, como una voz entre otras muchas que nos rodean y a las que estamos tan acostumbrados». Como María, la hermana de Marta y de Lázaro, que, «sentada junto a los pies del Señor, escuchaba su palabra» (Lc 10, 39), tenemos que escuchar sus palabras porque son suyas, tenemos que acogerlo a él.

El encuentro personal con Jesucristo es una gracia que requiere ser cultivada. La atracción por Jesús crece en el trato frecuente, en el conocimiento cada vez más profundo, hasta convertirse en entusiasmo y apasionamiento. El Papa muestra a los jóvenes cómo la relación de fe con Jesucristo se va haciendo más firme y más vivificante. «Queridos jóvenes, escuchad de verdad las palabras del Señor para que sean en vosotros 'espíritu y vida' (Jn 6, 63), raíces que alimentan vuestro ser, pautas de conducta que nos asemejen a la persona de Cristo, siendo pobres de espíritu, hambrientos de justicia, misericordiosos, limpios de corazón, amantes de la paz. Hacedlo cada día con frecuencia, como se hace con el único Amigo que no defrauda y con el que queremos compartir el camino de la vida. Bien sabéis que, cuando no se camina al lado de Cristo, que nos guía, nos dispersamos por otras sendas, como la de nuestros propios impulsos ciegos y egoístas, la de propuestas halagadoras pero interesadas, engañosas y volubles, que dejan el vacío y la frustración tras de sí» (Homilía en Cibeles). 


\section{Superar dificultades}

Prestar atención a la llamada, cultivar la atracción por Jesucristo, perseverar en la respuesta no es fácil. Benedicto $\mathrm{XVI}$ recordó más de una vez, a lo largo de la JMJ, los estorbos que podemos encontrar todos. A todos -jóvenes y mayores, los que participamos en la vida de la Iglesia y los que participan menos o nadanos tienta la autosuficiencia, la superficialidad, el desinterés por la verdad y la justicia, dejándonos abocar a «algo tan evanescente como una existencia sin horizontes, una libertad sin Dios» (Homilía en Cibeles). El primer día de su llegada había denunciado ya los estorbos externos con los que se pretende impedir que el Señor sea escuchado y seguido: «No pocos, por causa de su fe en Cristo, sufren en sí mismos la discriminación, que lleva al desprecio y a la persecución abierta o larvada que padecen en determinadas regiones y países. Se les acosa queriendo apartarlos de él, privándolos de los signos de su presencia en la vida pública, y silenciando hasta su santo Nombre. Pero yo vuelvo a decir a los jóvenes, con todas las fuerzas de mi corazón: que nada ni nadie os quite la paz; no os avergoncéis del Señor» (Discurso de bienvenida en Barajas).

Al principio de la Vigilia en Cuatro Vientos, después de escuchar el testimonio de unos cuantos jóvenes, el Papa se hace eco de las dificultades: «Pero, ¿cómo puede un joven ser fiel a la fe cristiana y seguir aspirando a grandes ideales en la sociedad actual? En el evangelio que hemos escuchado, Jesús nos da una respuesta a esta importante cuestión: 'Como el Padre me ha amado, así os he amado yo; permaneced en mi amor' (Jn 15, 9)».

Es decir que las dificultades que podemos encontrar en la sociedad actual -iy en nosotros mismos!- para vivir con fidelidad nuestra relación con el Señor, se superan acogiendo con gozo y agradecimiento el amor que él nos tiene. «Permanecer en su amor -continúa el Papa- significa entonces vivir arraigados en la fe, porque la fe no es la simple aceptación de unas verdades abstractas, sino una relación íntima con Cristo que nos lleva a abrir nuestro corazón a este misterio de amor y a vivir como personas que se saben amadas por Dios».

\section{Desear avanzar}

El hecho de que el encuentro personal con Jesucristo sea un acontecimiento de fe no lo hace menos real, sino más. Al joven creyente, que se siente concernido de manera personal por la llamada de Jesús, el Papa se atreve a proponerle, como quizá no todos los educadores y sacerdotes se atrevan, las exigencias del camino que se abre ante él. «Fe y seguimiento de Cristo están estrechamente relacionados. Y, puesto que supone seguir al Maestro, la fe tiene que consolidarse y crecer, hacerse más profunda y madura, a medida que se intensifica y fortalece la relación con Jesús, la intimidad con él. También Pedro y los demás apóstoles tuvieron que avanzar por este camino, hasta que el en- 
cuentro con el Señor resucitado les abrió los ojos a una fe plena» (Homilía de la Misa en Cuatro Vientos).

Y no sólo se superan las dificultades. El amor de Dios hace crecer y lleva a la plenitud: «Si permanecéis en el amor de Cristo, arraigados en la fe, encontraréis, aun en medio de contrariedades y sufrimientos, la raíz del gozo y la alegría. La fe no se opone a vuestros ideales más altos, al contrario, los exalta y perfecciona. Queridos jóvenes, no os conforméis con menos que la Verdad y el Amor, no os conforméis con menos que Cristo» (Vigilia). "Seguros de su amor, dice a los jóvenes polacos, acercaos a él con la llama de vuestra fe. Él os colmará de su vida. Edificad vuestra vida sobre Cristo y su Evangelio».

\section{Entregar la vida}

Permaneciendo en el amor de Cristo como amigos, perseverando en la oración -«tratar de amistad, estando muchas veces tratando a solas con quien sabemos nos ama», se recordaba a santa Teresa de Jesús-, se descubre la forma de vida a la que el Señor llama a cada uno y se encuentra la motivación para el seguimiento generoso. Por eso invitaba el Papa a continuación a los jóvenes a adorar a Cristo, realmente presente en la Eucaristía, a dialogar con él, a poner ante él todas sus preguntas y a escucharlo. Y siguió el momento más recordado sin duda de la JMJ 2011, el silencio más conmovedor, la oración más intensa. La resume el ritornello del himno de la Jornada: «Oh Cristo, nuestro Hermano, oh Cristo, nuestro Amigo, nuestro Señor, ¡haznos firmes en Ti!».

En el encuentro personal con Jesús que Benedicto XVI quiere propiciar hay, de un lado, llamada del Señor y escucha de los jóvenes, y de otro, debe haber respuesta. El Papa, que ha presentado la llamada en el contexto cultural, en la conciencia de los jóvenes, en los signos de la Iglesia, propone también las palabras, los sentimientos y las decisiones para que los mismos jóvenes configuren su respuesta: «Queridos jóvenes, también hoy Cristo se dirige a vosotros con la misma pregunta que hizo a los apóstoles: 'Y vosotros, ¿quién decís que soy yo?'. Respondedle con generosidad y valentía, como corresponde a un corazón joven como el vuestro. Decidle: 'Jesús, yo sé que Tú eres el Hijo de Dios que has dado tu vida por mí. Quiero seguirte con fidelidad y dejarme guiar por tu palabra. Tú me conoces y me amas. Yo me fío de ti y pongo mi vida entera en tus manos. Quiero que seas la fuerza que me sostenga, la alegría que nunca me abandone'».

\section{LA LLAMADA DE DIOS: SERVIDORES Y TESTIGOS EN MEDIO DEL MUNDO}

Únicamente quien ha escuchado una llamada puede responder. Sólo quien se sabe amado y buscado por el Señor puede sentirse impulsado a corresponder al amor recibido. Por eso en el argumento de Benedicto XVI sobre la voca- 
ción, todo arranca del reconocimiento de la llamada de Dios inscrita en la naturaleza humana; continúa en Jesucristo, que hace más clara la llamada, muestra el camino de la respuesta invitando a unirse a él y a su misión y da fuerza para recorrerlo, y culmina con la plenitud humana y el gozo que se concede a quien responde con generosidad.

Así lo resume al iniciar la homilía de la Misa en Cuatro Vientos, pieza central en su mensaje junto con la homilía de la víspera en la Vigilia. «Sí, el Señor os quiere y os llama amigos suyos (cf. Jn 15, 15). Él viene a vuestro encuentro y desea acompañaros en vuestro camino, para abriros las puertas de una vida plena, y haceros partícipes de su relación íntima con el Padre. Nosotros, por nuestra parte, conscientes de la grandeza de su amor, deseamos corresponder con toda generosidad a esta muestra de predilección con el propósito de compartir también con los demás la alegría que hemos recibido».

En la Iglesia, propiamente, no se necesitan voluntarios que trabajen por difundir una buena doctrina, reparar las injusticias o hacer el bien. Lo que la Iglesia desea es que haya testigos del Evangelio; es decir, personas que han conocido a Jesucristo, han puesto su confianza en él, viven desde entonces como si hubieran vuelto a nacer, y se sienten urgidos a compartir con otros lo que les ha sucedido a ellos. Saben que es el mayor servicio que pueden prestar.

Uno de los objetivos pastorales de la JMJ es justamente el de contribuir a que los jóvenes se conviertan en evangelizadores y misioneros del mundo contemporáneo. Y a ese objetivo se refiere el último párrafo de la homilía del 21 de agosto, en el que Benedicto XVI viene a resumir el núcleo de su mensaje: «De esta amistad con Jesús nacerá el impulso que lleva a dar testimonio de la fe en los más diversos ambientes, incluso allí donde hay rechazo o indiferencia. No se puede encontrar a Cristo y no darlo a conocer a los demás. Por tanto, no os guardéis a Cristo para vosotros mismos. Comunicad a los demás la alegría de vuestra fe... 'Id al mundo entero y proclamad el Evangelio a toda la creación' (Mc 16, 15). También a vosotros os incumbe la extraordinaria tarea de ser discípulos y misioneros de Cristo en otras tierras y países donde hay multitud de jóvenes que aspiran a cosas más grandes y, vislumbrando en sus corazones la posibilidad de valores más auténticos, no se dejan seducir por las falsas promesas de un estilo de vida sin Dios».

\section{Insertos en el mundo}

El deseo de responder a la llamada de Dios no distrae a los jóvenes creyentes de la realidad que están viviendo junto con sus compañeros. La fe, lejos de desdibujar la realidad de la vida, da una mirada más penetrante para contemplar sus posibilidades y limitaciones. Superficialidad, consumismo, hedonismo, banalidad a la hora de vivir la sexualidad, insolidaridad, corrupción... marcan una conducta que tienta a todos. Quienes se sienten atraídos por Dios afrontan la 
tentación como un desafío. Responder a Dios con fidelidad los lleva a enraizarse en el mundo. Ni escapan ni aniquilan; quieren transformar. En la amistad con Dios encuentran luz para caminar, razones para esperar, la más poderosa motivación para comprometerse con toda generosidad en la construcción de una sociedad en la que se respete la dignidad humana y la fraternidad.

Son muchos los jóvenes que, «fiándose por entero de Cristo, saben que tienen realmente un futuro por delante y no temen los compromisos decisivos que llenan toda la vida», dice el Papa al saludar a los autoridades en Barajas.

El creyente, que ha conocido a Dios y vive confiado en él, da testimonio -por supuesto- de que Dios existe, de lo que Dios ha hecho en su Hijo Jesucristo a favor nuestro, y de la transformación, la salvación, que la acción de Dios ha operado en nosotros. Y, por lo tanto, de lo que estamos llamados a ser, de la transformación que Dios quiere realizar de la realidad introduciendo su Novedad en nuestra historia. A través del testimonio se comparte lo que se ha recibido, se ofrece la salvación que Dios ha prometido y de la que nos estamos beneficiando. El testimonio no consiste sólo en hablar de ello; también en hacerlo y, sobre todo, vivirlo, en el convencimiento de que dar testimonio de nuestra fe es el mejor servicio que podemos prestar.

\section{Responder con la vida}

Así, en el discurso a los profesores universitarios reunidos en el monasterio de El Escorial, recuerda el Papa la realidad que hay que transformar: para muchos hoy, la misión del profesor universitario se reduce a formar técnicos, profesionales competentes que satisfagan la demanda laboral. Y a continuación muestra el qué y el porqué de la vocación universitaria. "Sentís sin duda el anhelo de algo más elevado que corresponda a todas las dimensiones que constituyen al hombre... Tenéis el honor y la responsabilidad de transmitir ese ideal universitario: un ideal que habéis recibido de vuestros mayores, muchos de ellos humildes seguidores del Evangelio. Debemos sentirnos sus continuadores en una historia bien distinta de la suya, pero en la que las cuestiones esenciales del ser humano siguen reclamando nuestra atención e impulsándonos hacia adelante. Con ellos nos sentimos unidos a esa cadena de hombres y mujeres que se han entregado a proponer y acreditar la fe ante la inteligencia de los hombres. Y el modo de hacerlo no solo es enseñarlo, sino vivirlo, encarnarlo, como también el Logos se encarnó para poner su morada entre nosotros». Un poco más adelante comenta el servicio de los profesores: «La enseñanza no es una escueta comunicación de contenidos, sino una formación de jóvenes a quienes habéis de comprender y querer, en quienes debéis suscitar esa sed de verdad que poseen en lo profundo y ese afán de superación. Sed para ellos estímulo y fortaleza».

Más contundente es, en la misma línea, la consideración que Benedicto XVI hace al finalizar el Viacrucis: «'Cristo me amó y se entregó por mí' (Gal 2, 20). 
Ante un amor tan desinteresado, llenos de estupor y gratitud, nos preguntamos ahora: ¿Qué haremos nosotros por él? ¿Qué respuesta le daremos? San Juan lo dice claramente: 'En esto hemos conocido el amor: en que él dio su vida por nosotros. También nosotros debemos dar nuestra vida por los hermanos' (1 Jn $3,16) »$. En seguida la referencia a la realidad que ha de ser asumida, transformada y vivida según Dios. «No paséis de largo ante el sufrimiento humano, donde Dios os espera para que entreguéis lo mejor de vosotros mismos: vuestra capacidad de amar y de compadecer. Las diversas formas de sufrimiento que, a lo largo del Vía Crucis, han desfilado ante nuestros ojos son llamadas del Señor para edificar nuestras vidas siguiendo sus huellas y hacer de nosotros signos de su consuelo y salvación».

El paso por la Fundación Instituto San José, antes de la Vigilia en Cuatro Vientos, fue una nueva oportunidad para recordar brevemente cómo llegan hasta nosotros las llamadas de Dios y cómo puede brotar nuestra respuesta. Primero, ver la predilección del Señor por el que sufre; segundo, dejarnos encontrar personalmente por Cristo, que ama así; tercero, transformados por ese encuentro, mirar al que sufre con ojos limpios y darle, además de las cosas externas, la mirada de amor que necesita. Luego, experimentar la grandeza a la que está llamado quien se compadece.

En la Vigilia de Cuatro Vientos dirige el Papa a los jóvenes el llamamiento más apremiante. A veces se insinúa la sospecha de que la evangelización en la que la Iglesia llama a participar en nombre de Jesucristo lleva consigo la confrontación e incluso la negación de valores humanos. Bien al contrario, los purifica y los libera. El anuncio de Jesucristo, como salvador de todos los hombres y fuente de esperanza para nuestra vida, impulsa la búsqueda de la verdad, que es la aspiración más alta del espíritu humano; al mismo tiempo, es verdad, libera del relativismo que renuncia a la búsqueda de la verdad y la desprecia. Esto es lo que a veces desencadena dificultades y persecuciones. «Queridos amigos, que ninguna adversidad os paralice. No tengáis miedo al mundo, ni al futuro, ni a vuestra debilidad. El Señor os ha otorgado vivir en este momento de la historia, para que gracias a vuestra fe siga resonando su Nombre en toda la tierra. Vale la pena acoger en nuestro interior la llamada de Cristo y seguir con valentía y generosidad el camino que él nos proponga».

Justo antes de regresar a Roma, plantea Benedicto XVI a los voluntarios el tema del discernimiento de la vocación; lo hace coloquialmente, pero no deja de ser incisivo: «Al volver ahora a vuestra vida ordinaria, os animo a que guardéis en vuestro corazón esta gozosa experiencia y a que crezcáis cada día más en la entrega de vosotros mismos a Dios y a los hombres. Es posible que en muchos de vosotros se haya despertado tímida o poderosamente una pregunta muy sencilla: ¿Qué quiere Dios de mí? ¿Cuál es su designio sobre mi vida? ¿Me llama Cristo a seguirlo más de cerca? ¿No podría yo gastar mi vida entera en la misión de anunciar al mundo la grandeza de su amor a través del sacer- 
docio, la vida consagrada o el matrimonio? Si ha surgido esa inquietud, dejaos llevar por el Señor y ofreceos como voluntarios al servicio de Aquel que «no ha venido a ser servido sino a servir y a dar su vida como rescate por muchos» (Mc 10, 45). Vuestra vida alcanzará una plenitud insospechada». El esquema es el habitual: encuentro gozoso con el Señor, llamada que debe ser discernida, promesa de plenitud.

La vocación a la vida consagrada fue el tema de la reunión con jóvenes religiosas en El Escorial. Nace, como las demás vocaciones cristianas particulares, de la escucha de la Palabra de Dios y quiere responder con una vida que tiene el Evangelio como norma que la inspira. En este sentido, el vivir siguiendo a Cristo casto, pobre y obediente, se convierte en «exégesis» viva (interpretación, explicación) de la Palabra de Dios... (cf. Ex. apostólica Verbum Domini, 83).

\section{La vida consagrada}

La vocación a la vida consagrada, independientemente de las tareas que desarrolle quien responde a ella, es vocación a evangelizar. En ella se anuncia como buena noticia la radicalidad de la pertenencia a Dios, sumamente amado; es luz potentísima que desenmascara la inhibición y la mediocridad del relativismo que a veces parece dominar en el ambiente. La radicalidad de la pertenencia a Dios se expresa en la comunión filial con la Iglesia y en la dedicación a la misión que Dios ha querido confiar a los consagrados: tanto la vida contemplativa como los diversos caminos de vida apostólica en la educación de niños y jóvenes, el cuidado de los enfermos y ancianos, el acompañamiento de las familias, el compromiso a favor de la vida, el testimonio de la verdad, el anuncio de la paz y la caridad, la labor misionera y la nueva evangelización, y tantos otros campos del apostolado eclesial.

Esta vida de seguimiento cercano e incondicional a Jesucristo en la consagración, comunión y misión, que es tan necesaria en Iglesia, interpela sin duda fuertemente a los jóvenes y los alienta e ilumina.

\section{Ministerio ordenado}

La vocación al sacerdocio ministerial fue comentada en particular en la misa que celebró el Papa con seminaristas en la Catedral de la Almudena. En la homilía va resaltando el Santo Padre algunos aspectos de la vocación y de la vida de los presbíteros. El primero de ellos es el encuentro personal con Cristo, quien por su encarnación es revelador de Dios y por su resurrección es cumplidor fiel de su promesa.

El aspecto más importante es el de la configuración con Cristo. Igual que Cristo, el Sacerdote único al que representa, el presbítero hace de su existencia una ofrenda total; la celebración de la Eucaristía es el signo. «Configurarse con 
Cristo comporta, queridos seminaristas, identificarse cada vez más con Aquel que se ha hecho por nosotros siervo, sacerdote y víctima. Configurarse con él es, en realidad, la tarea en la que el sacerdote ha de gastar toda su vida. Ya sabemos que nos sobrepasa y no lograremos cumplirla plenamente, pero, como dice san Pablo, corremos hacia la meta esperando alcanzarla (cf. Flp 3, 12-14)». La configuración con Cristo, Buen Pastor que da la vida por sus ovejas, implica poner a su disposición la totalidad de la persona. «Esta disponibilidad, que es don del Espíritu Santo, es la que inspira la decisión de vivir el celibato por el Reino de los cielos, el desprendimiento de los bienes de la tierra, la austeridad de vida y la obediencia sincera y sin disimulo». Así puede el presbítero salir a buscar a alejados y pecadores, permanecer cerca de los pobres y los enfermos.

Tampoco se olvida aquí la promesa de plenitud humana y de alegría que acompaña a quienes, a pesar de las dificultades, colaboran en la obra de Dios. «Afrontad este reto sin complejos ni mediocridad, antes bien como una bella forma de realizar la vida humana en gratuidad y servicio, siendo testigos de Dios hecho hombre, mensajeros de la altísima dignidad de la persona humana y, por consiguiente, sus defensores incondicionales». «Puede que os menosprecien, como se suele hacer con quienes evocan metas más altas o desenmascaran los ídolos ante los que hoy muchos se postran. Será entonces cuando una vida hondamente enraizada en Cristo se muestre realmente como una novedad y atraiga con fuerza a quienes de veras buscan a Dios, la verdad y la justicia».

\section{Matrimonio}

La llamada al matrimonio es presentada expresamente a los jóvenes en la Vigilia de Cuatro Vientos: «A muchos, el Señor los llama al matrimonio, en el que un hombre y una mujer, formando una sola carne (cf. Gn 2, 24), se realizan en una profunda vida de comunión. Es un horizonte luminoso y exigente a la vez. Un proyecto de amor verdadero que se renueva y ahonda cada día compartiendo alegrías y dificultades, y que se caracteriza por una entrega de la totalidad de la persona. Por eso, reconocer la belleza y bondad del matrimonio, significa ser conscientes de que solo un ámbito de fidelidad e indisolubilidad, así como de apertura al don divino de la vida, es el adecuado a la grandeza y dignidad del amor matrimonial».

No es novedad en la Iglesia hablar de la vocación al matrimonio. Puede ser más nuevo invitar a los jóvenes a discernir si Dios los llama al matrimonio y a responder con valentía y generosidad, porque con frecuencia se da por supuesto que el matrimonio «sobreviene» naturalmente sin necesidad de campañas vocacionales. La llamada es a hacer presente el amor de Dios a la humanidad, el amor de Cristo a la Iglesia. Es llamada al sacramento, a entregar al marido o a la esposa la totalidad de la propia persona y a acoger la entrega del otro, en una vida de comunión. Es llamada a entregarse como se entrega Dios: del todo 
y con una fidelidad irreversible a pesar de las dificultades y debilidades, y para dar vida. Todos en la Iglesia y en la sociedad han de poder percibir en el matrimonio y la familia el signo del amor de Dios.

\section{En Iglesia}

Los jóvenes, con todo, necesitan ayuda para permanecer firmes en la fe y asumir la bella aventura de anunciarla y testimoniarla abiertamente con su propia vida. Su testimonio necesita temple, ha de ser valiente y decidido, pero más atento a las necesidades de los hermanos que a uno mismo; sin ocultar que se es cristiano, pero respetando y haciéndose respetar por quienes sostengan otras opciones legítimas. Esta ayuda la encontrarán, Dios lo quiera, en cristianos adultos que permanezcan cerca. Esta ayuda la encontrarán ciertamente «en la comunión de la Iglesia. No se puede seguir a Jesús en solitario (el Papa en la misa de Cuatro Vientos). Quien cede a la tentación de ir 'por su cuenta' o de vivir la fe según la mentalidad individualista, que predomina en la sociedad, corre el riesgo de no encontrar nunca a Jesucristo, o de acabar siguiendo una imagen falsa de él. Tener fe es apoyarse en la fe de tus hermanos, y que tu fe sirva igualmente de apoyo para la de otros... Es fundamental vuestra gozosa inserción en las parroquias, comunidades y movimientos, así como la participación en la Eucaristía de cada domingo, la recepción frecuente del sacramento del perdón y el cultivo de la oración y meditación de la Palabra de Dios».

Al despedir a la muchedumbre de jóvenes después del Ángelus, Benedicto $\mathrm{XVI}$ terminó repitiendo en varios idiomas el llamamiento a anunciar por todo el mundo, con la palabra y la vida, el Evangelio que había sido proclamado, confesado, vivido y celebrado en una inolvidable fiesta de fe, fiesta de la Iglesia. 